\title{
AC 2010-1805: OUTSOURCING IN NEXT GENERATION TECHNICAL SOFTWARE ENGINEERING EDUCATION
}

\section{James Long, Oregon Institute of Technology}

James Long is an Associate Professor in the Software Engineering Technology program at Oregon Institute of Technology. James has been teaching at OIT for 10 years. Before coming to OIT, James worked in industry for 15 years as a Software Engineer. James has extensive industry experience in Large Scale Software Systems, Telecommunications, Medical Systems, and Real Time Data Acquisition and Dissemination. 


\title{
Outsourcing in Next Generation Software Engineering Technology Education
}

\begin{abstract}
Outsourcing is gaining an increasing presence in the US software development industry. As the Internet develops in emerging economies, the infrastructure required for effective outsourcing is maturing. The US software development workforce is now faced with viable competition from countries where software developer salaries are lower by an order of magnitude.

In technical software engineering education, code development is emphasized as a basis of laboratory exercises and hands-on experience. Outsourcing trends bring several challenges to the technical education table. As software engineering educators, how can we prepare our students for a workforce where a key aspect of the education we provide may prove irrelevant in the near future? This paper studies the issue of outsourcing in the software engineering educational environment as a required component of a software engineering project.

The first aspect presented is the outsourcing of a capstone project for the Bachelor of Science in Software Engineering Technology program to a developer or development team in an emerging economy. An operational process is presented showing how this was done to bring outsourcing as a viable activity for student projects. The second aspect examines application of the developed framework for outsourcing as a key component of developing large scale software systems. The junior project sequence is used as a test platform where five student teams are tasked with outsourcing a component of their project given a budget of $\$ 50.00$ per team. The outcome impacts their final grade. The results of this activity are presented and analyzed.
\end{abstract}

Outsourcing of software development will increase in the software development industry as Internet based support infrastructure matures. The topics explored here deal with how to embrace outsourcing trends to prepare students for globally distributed software development.

\section{Program Description}

The Computer Systems Engineering Technology department of Oregon Institute of Technology (OIT) offers a four year Bachelor of Science degree in Software Engineering Technology. OIT is accredited through Northwest Accrediting Agency. The Software Engineering Technology degree is accredited through the Accrediting Board for Engineering and Technology (ABET). The definition of engineering technology considered for construction of the curriculum is described in the Commission on Engineering and Technical Systems publication titled Engineering Education and Practice in the United States: Engineering Technology Education ${ }^{1}$ :

Engineering technology focuses on knowledge of mathematics and natural sciences gained by higher education, experience, and practice as devoted to the implementation and extension of existing technology for the benefit of humanity. 
Engineering technology education focuses on applied science and engineering and application of theory in real-world problems. Courses are aimed at preparing graduates for practice in a specific field of the technological spectrum. Courses are laboratory based and have a high component of practical practice and practical application. Hands-on experience is stressed in an educational environment targeted at producing "job ready' graduates.

As a degree program in Software Engineering Technology, the developed curriculum offers laboratory based courses in hardware construction and design and software construction and design. Class sizes are targeted at 20 students. Laboratories are taught by the professors giving lectures. All students, Computer Engineering Technology (computer hardware construction and design), Software Engineering Technology (software construction and design), and Embedded Systems Engineering Technology (core systems hardware design/software design and integration), take a common first year of courses. In the second year, students branch into one of the three bachelor of science programs listed offered. By the end of the second year, students are well versed in program design and construction with $\mathrm{C}, \mathrm{C}++$ and assembly language.

The third year of the program focuses on large scale systems analysis, design, construction, deployment, testing and quality assurance. The core of this activity is a three term course sequence encompassing team based construction of a real-world enterprise scale system. The projects worked on are based on problems derived from on campus research projects or industry partners.

The Software Engineering Technology program at OIT has approximately 100 students enrolled in the four years. The program draws students directly out of high school. Students normally have exposure to computer programming and a high level of interest in becoming "programmers". By the end of the second year, there is a feeling that this has been achieved, so there is a need to redirect "programming" ideas toward interest in becoming "software engineers". The Junior and Senior project sequence courses perform this task of redirection. Since the Junior Project sequence is team based and at a time the students are beginning to get the larger scope of software engineering, it is an excellent place to broaden student horizons beyond programming as a profession and the borders of the United States as a geographic limitation for a software development team.

\section{Description of Outsourcing Activity Need}

The outsourcing assignment need is driven from two different directions. These are the directions of software development trends in United States industry and ABET program requirements for international communication and collaboration.

Software development in the Unites States is trending toward moving software development to locations outside of the country as a cost savings measure. Software developers in emerging economies will work for a wage an order of magnitude less than wages required of software engineers in the United States. A recent project put up for bid in the Rent-A-Coder web site (www.rentacoder.com) came in with qualified developers willing to take on the project for $\$ 0.15 / \mathrm{hr} \mathrm{USD}^{2}$. A similarly qualified software developer in the United States cost $\$ 25.00 / \mathrm{hr}$. A 
poll taken in 2006 indicated that of all polled companies located in the Unites States, $61 \%$ were managing active software development outsourcing projects. Of this $61 \%$, only $7 \%$ planned to decrease future software development outsourcing activities ${ }^{3}$. The economic downturn of 2009 certainly impacted the software development outsourcing market; however, a recent poll of software outsourcing service providers in the third quarter of 2009 shows $75 \%$ have growth in their project deal pipeline. This is up 10\% from the second quarter of 2009 and up 34\% from the third quarter in $2008^{4}$. Outsourcing of software development projects, even in the face of severe economic conditions, continues to grow. In light of these software industry developments, good computer programming skills will not keep bachelors degree holding software engineers in a job.

From the Accrediting Engineering and Technology Programs, Computer Engineering Technology program, the following program outcomes are directly targeted and continuously applicable to the outsourcing exercise:

a. an appropriate mastery of the knowledge, techniques, skills, and modern tools of their disciplines

e. an ability to function effectively on teams

g. an ability to communicate effectively

j. a respect for diversity and a knowledge of contemporary professional, societal and global issues $^{5}$

The above items are addressed as follows:

- Item a: This is addressed in the use of the Internet as a tool for communicating a technical problem to individuals in a remote environment, the solicitation of help with a solution, and the eventual installation and deployment of the remotely developed solution.

- Item $\boldsymbol{e}$ : The team work aspect of the project sequence is augmented by the outsourcing exercise by bringing in a worker to be integrated into the project as a transient team member.

- Item $g$ : The communication aspect of working with a software developer that has English as a second language drives home the importance of software requirements and precise specifications.

- Item $j$ : This is addressed in the employment of a software developer from a country with an emerging economy. Through the exercise, students gain the understanding that there are software development workers fully educated and employed in software development outside the confines of the United States software development industry.

The outsourcing project for the junior project sequence was developed to explore emerging trends in the software engineering profession. Outsourcing and distributed off-shore software development is to be seen as a resource, not a threat. ABET requirements fit nicely into the outsourcing assignment, bringing global communications and offshore teamwork into the learning environment.

\section{Course Description for Outsourcing Project Application}

The outsourcing assignment is given in the third term of the third year (junior year) of the program. The third year requires students to take a three term sequence of courses. In these 
courses, students develop and deploy a large scale software project for a real-world client while learning team based software skills in:
a. Requirements Gathering
b. Functional Architecture
c. Use Case Analysis
d. Functional to Object Mapping through Sequence Diagram Analysis
e. Test Case Generation through Scenario Analysis
f. Logical Architecture
g. Class Modeling
h. Component Architecture
i. Component Modeling
j. Physical Architecture
k. Project Scheduling, Release Scheduling and Resource Management
1. System Deployment and Maintenance
m. Quality Assurance

The first term encompasses items a, b, c, j, k and $\mathrm{m}$. The second term encompasses items c, d, e, $\mathrm{f}, \mathrm{g}, \mathrm{h}, \mathrm{i}, \mathrm{j}$, and $\mathrm{m}$. The third term encompasses items i, j, k, l, and $\mathrm{m}$. The development process used falls under the realm of Agile Software Development.

Prior to the start of first term, the professor for the course sequence works with research partners at the university and industry contacts to put together enough sponsored projects to break the class into teams containing three to four individuals. Students in the course sequence are presented with a selection of projects from which to choose early in the first term. These projects will form the basis for the entire year, providing a platform on which software engineering topics are developed. This is done early in the first term of the sequence. Students self organize into project teams under supervision of the course professor.

Project development takes place during the three term sequence. The goal for the end of the year is for the project teams to produce a final release candidate of their system. This requires them to produce an alpha release, a beta release, and, from the beta release, prioritize and fix system problems, then create a system install set. The first revision systems are then deployed in their final versions by the end of the spring term.

\section{Project Outsourcing Description and Assignment}

The outsourcing assignment is given to the class in the first week of the third term. Project teams have the entire term to execute and report on the exercise. The web site http://www.rentacoder.com ${ }^{2}$ was used as the outsourcing agent for the project. This service provides the ability to post project specifications as a request for proposal and hire a developer or team of developers to work on the project. The Rent-A-Coder service will escrow project funds, ensuring the developers they will be paid upon successful completion of the project. The following sequence of events is supported through the Rent-A-Coder site:

1. A project team will register with the Rent-A-Coder site as a project requester.

2. The project team will post project requirements specifications and description to the site. 
3. Developers registered with Rent-A-Coder bid on the project. Currently, Rent-A-Coder has $\sim 300,000$ registered coders from all over the world. ${ }^{2}$

a. During the bidding processes, developers ask questions about the project to gain more insight on what is involved.

b. Project posters must provide additional information to gain confidence from bidders. This activity is key in getting students to understand the importance of sound requirements and specifications that can be understood.

c. Forcing projects to be posted to "English as a Second Language" coders increases the communication requirements.

4. Project requesters then choose a developer or team of developers to work on the project. At this point in time, funds are placed in an escrow account for the project.

5. Communication continues with the hired developer through a communication system provided by the Rent-A-Coder site. This helps students with the journaling of project outcome.

6. When the project team is happy with the work done by the hired coder, the project requester will accept the coders work as complete and release funds for payment of the coder.

As a result of the project, students are to deliver:

- Project Requirements Specification for the outsourced project

- Project Posting to Rent-a-Coder

- Chosen Coder Decision Factors

- Outsourced Project Journal

- Final Outsourced Project Code Base

- Final Outsourced Project Write-up

In addition to these deliverables, the project teams present to the class their outsource proposal before the project is outsourced and their final results upon completion of the outsource project.

\section{Project Descriptions for 2008-2009}

The first time for the outsourcing project assignment was Spring term in the 2008-2009 school year. The projects that were being worked on are listed below along with a brief description of each. Following the project descriptions are a brief outsourcing project description.

\section{$\underline{\text { Robotics Project: }}$}

The Manufacturing and Mechanical Engineering programs have a project dealing with the reengineering of old surplus articulated arm robots into robotic platforms that can support the current manufacturing courses and labs on campus. The robots are being rebuilt with new control boards, servos, and motors. The enterprise software project is to:

1. Create the control libraries allowing the robots to be programmed and controlled.

2. Create a user interface allowing an end user to write control scripts for the robots.

3. Build a simulation environment allowing users to program the robot virtually.

4. Create a web presence allowing the robots to be programmed and operated through a web site. 
The piece of the project outsourced was a component written in C\# allowing the saving and loading of XML scripts from a disk file. The component was directly integrated with a control component for scripting robot operation.

\section{DICOM to HL-7 Protocol Translation:}

The Medical Imaging department has a working Health Information System (HIS) called GE Centricity and a Picture Archival Communication System (PACS) created by FUJI. The HIS system communicates through the network using the Health Level 7 (HL7) Protocol Standard and the PACS communicates using the Digital Imaging Communication of Medicine 3.0 (DICOM 3.0) Protocol Standard. In these two systems, there is information common across both systems. Integration requires a layer 7 protocol bridge to maintain information integrity in an environment where HIS and PACS must coexist. The project is to build an intermediary, web based system that can effectively perform protocol translation between the HL7 and DICOM 3.0 standard communications for synchronization of health care records. Initial system should be tested using open source PACS (MyFreePACS) and HIS (OpenMRS).

The piece of the project outsourced as described and posted by the students entailed writing a server component in $\mathrm{C \# ,} \mathrm{C}++$, or Java to read information from a $\mathrm{C}++$ object and create an XML data stream and writing a client php script to read the XML data stream and display the contained information in a web form.

\section{Hybrid Vehicle Control:}

The Mechanical Engineering department has received a sponsorship from a member of the Bonneville Power Agency of Oregon to produce a plug in hybrid conversion kit for older automobiles that are reaching the end of their service life. This kit would allow a car mechanics enthusiast to purchase a crate of parts and, following a set of instructions, convert the older vehicle into a new, fuel efficient, plug-in hybrid vehicle. The piece of this kit provided by the software/embedded systems team will be the control system allowing the diesel engine and the electric motor to work independently or in conjunction for the propulsion of the vehicle. The developed system will contain:

1. Motor controller interfaces for starting, speeding up, slowing down, and stopping both power sources.

2. Sensor interfaces for operational parameters of the vehicle.

3. Control algorithms for optimization of vehicle performance for power and fuel efficiency.

4. Gathering and storage of all sensor information in the vehicle.

5. Wireless telemetry of operational parameters for vehicle testing, tracking, route finding, and fuel consumption control.

The piece of the project outsourced as described and posted by the students was an XML generator in $\mathrm{C}++$ to create an XML data stream from a pre defined data structure.

\section{Distributed Chess Tournament:}


A chess board was created by students in the Computer Engineering Technology department that records the moves of chess pieces and sends the recorded data to a host computer though a Bluetooth connection. This allows a remote user to view the progress of the game. The board also supports the sending of move information from the host computer that will cause the piece on the board and the squares for the move to light up. This allows a remote user to play a game on the physical board without being act the board with the help of the individual at the physical board.

This system is to be expanded through an enterprise software system so distributed chess tournaments can be run using the wireless chess board as the enabling technology. The web based system is to allow multiple chess boards to register with a host computer. Each game in the tournament is then represented on a tournament web site and the moves for the board are recorded for later playback. The system will also allow a remote user to participate in the tournament through a graphical interface where the remote user will use a web browser and a pointing device (such as a mouse) to manipulate the virtual pieces.

The piece of the project outsourced as described and posted by the students was a complete redesign of the web site look and feel.

\section{Project Outsourcing Outcome for 2008}

During the outsourcing projects, the instructor monitored the outsourcing site and watched the dialog between the project teams and the outsource programmer. This communication was used to determine proficiency in the four targeted assignment outcomes. In addition to the outsource site dialog, the outcome of the outsource project and the deliverable results, were also used to evaluate a rubric bases assessment of each project. The rubric used is shown below:

\begin{tabular}{|c|c|c|c|c|c|}
\hline $\begin{array}{l}\text { Performance } \\
\text { Criteria }\end{array}$ & $\begin{array}{l}\text { Limited or No } \\
\text { Proficiency (1) }\end{array}$ & $\begin{array}{c}\text { Some Proficiency } \\
\text { (2) }\end{array}$ & Proficiency (3) & $\begin{array}{c}\text { High Proficiency } \\
\text { (4) }\end{array}$ & Score \\
\hline $\begin{array}{l}1 \text { - Using of } \\
\text { Internet based } \\
\text { tools as a means } \\
\text { for project } \\
\text { communications. }\end{array}$ & $\begin{array}{l}\text { Struggled with } \\
\text { the use of the } \\
\text { outsource agent } \\
\text { site as a means } \\
\text { for distributed } \\
\text { project } \\
\text { management. }\end{array}$ & $\begin{array}{l}\text { Used the outsource } \\
\text { agent site but } \\
\text { required special } \\
\text { attention by the } \\
\text { instructor. }\end{array}$ & $\begin{array}{l}\text { Used the } \\
\text { outsource agent } \\
\text { site for } \\
\text { communication } \\
\text { and effectively } \\
\text { completed the } \\
\text { project based on } \\
\text { the outsource site } \\
\text { alone. }\end{array}$ & $\begin{array}{l}\text { Extended the use } \\
\text { of the outsource } \\
\text { site through } \\
\text { integration of other } \\
\text { online team } \\
\text { collaboration tools. }\end{array}$ & \\
\hline $\begin{array}{l}2 \text { - Ability to } \\
\text { integrate a } \\
\text { remote team } \\
\text { member into the } \\
\text { project team. }\end{array}$ & $\begin{array}{l}\text { The outsource } \\
\text { programmer was } \\
\text { viewed as a } \\
\text { nuisance and not } \\
\text { included in } \\
\text { project discussion } \\
\text { and decisions. }\end{array}$ & $\begin{array}{l}\text { The outsource } \\
\text { programmer was } \\
\text { given a task and } \\
\text { completed the task; } \\
\text { however, there was } \\
\text { very little } \\
\text { intermediate } \\
\text { communication. }\end{array}$ & $\begin{array}{l}\text { The outsource } \\
\text { programmer was } \\
\text { included in } \\
\text { online team } \\
\text { discussions and } \\
\text { was part of the } \\
\text { decision process. }\end{array}$ & $\begin{array}{l}\text { The outsource } \\
\text { programmer made } \\
\text { project suggestions } \\
\text { and those ideas } \\
\text { were integrated } \\
\text { into the end } \\
\text { product. }\end{array}$ & \\
\hline $\begin{array}{l}\text { - Effective } \\
\text { communications } \\
\text { with a team } \\
\text { member that } \\
\end{array}$ & $\begin{array}{l}\text { Communication } \\
\text { was broken off } \\
\text { and often did not } \\
\text { transfer the }\end{array}$ & $\begin{array}{l}\text { Communication } \\
\text { was terse. Ideas } \\
\text { were transferred } \\
\text { yet with poor }\end{array}$ & $\begin{array}{l}\text { Communication } \\
\text { was effective. } \\
\text { There was no } \\
\text { help offered in }\end{array}$ & $\begin{array}{l}\text { Communication } \\
\text { was effective. A } \\
\text { willingness to help } \\
\text { the outsource agent }\end{array}$ & \\
\hline
\end{tabular}




\begin{tabular}{|l|l|l|l|l|l|}
\hline $\begin{array}{l}\text { Speaks English } \\
\text { as a second } \\
\text { language. }\end{array}$ & $\begin{array}{l}\text { desired } \\
\text { information. }\end{array}$ & attitude. & $\begin{array}{l}\text { English or advice } \\
\text { given to better } \\
\text { communication. }\end{array}$ & $\begin{array}{l}\text { with English skills } \\
\text { was evident. }\end{array}$ & \\
\hline $\begin{array}{l}\text { - - } \\
\text { Understanding } \\
\text { of outsource } \\
\text { coders culture, } \\
\text { work ethic, and } \\
\text { economic issues. }\end{array}$ & $\begin{array}{l}\text { Shows disrespect } \\
\text { for outsource } \\
\text { coder as } \\
\text { displayed through } \\
\text { communications } \\
\text { and in lecture/lab } \\
\text { conversation. }\end{array}$ & $\begin{array}{l}\text { Shows indifference } \\
\text { to the outsource } \\
\text { coder situations } \\
\text { and an } \\
\text { unwillingness to } \\
\text { adapt to differences } \\
\text { in work ethic and } \\
\text { geographic } \\
\text { limitations. }\end{array}$ & $\begin{array}{l}\text { Shows an } \\
\text { understanding of } \\
\text { the outsource } \\
\text { coder situation } \\
\text { and a willingness } \\
\text { to accommodate } \\
\text { differences in } \\
\text { work ethic and } \\
\text { geography. }\end{array}$ & $\begin{array}{l}\text { Shows a full } \\
\text { understanding of } \\
\text { outsource coder } \\
\text { situation and a } \\
\text { willingness to } \\
\text { learn more about } \\
\text { the environment in } \\
\text { which the coder } \\
\text { lives. }\end{array}$ & \\
\hline
\end{tabular}

An acceptable performance level was determined to be $80 \%$ of the groups getting 3 or above as an application of the above rubric.

Although the first run of the outsource project sample size results in statistically insignificant results, the outcome was as follows:

\begin{tabular}{|c|l|l|}
\hline Performance Criteria & \multicolumn{1}{|c|}{ Results } & \multicolumn{1}{c|}{ Comments } \\
\hline 1 & 1 at 4,3 at 3,1 at $1-80 \%$ & $\begin{array}{l}\text { Acceptable. The sub standard group had } \\
\text { never defined a team leader. The high } \\
\text { group used their own suite of tools to } \\
\text { augment Internet based team management. }\end{array}$ \\
\hline 2 & $\begin{array}{l}1 \text { at } 4,2 \text { at } 3,1 \text { at } 2,1 \text { at } 1 \\
-60 \%\end{array}$ & $\begin{array}{l}\text { Unacceptable. Two of the teams had a bad } \\
\text { attitude related to the use of an outsource } \\
\text { programmer. They were unwilling to bring } \\
\text { this third party into the team as a } \\
\text { contributing partner. }\end{array}$ \\
\hline 3 & 1 at 4,3 at 3,1 at $1-80 \%$ & $\begin{array}{l}\text { Acceptable. One of the discontent teams, } \\
\text { after work load reorganization, was able to } \\
\text { carry out communications. }\end{array}$ \\
\hline 4 & 2 at 4,1 at 3,2 at $2-60 \%$ & $\begin{array}{l}\text { Unacceptable. The two groups that } \\
\text { developed a bad attitude toward the } \\
\text { exercise never bought into the outsourcing } \\
\text { idea. Two of the groups made online } \\
\text { friendships with their outsource } \\
\text { programmer and took time to learn about } \\
\text { the outsource programmer culture, work } \\
\text { environment, and family life. }\end{array}$ \\
\hline
\end{tabular}

There were problem areas in outcomes; however, the overall outcome of the outsourcing exercise was considered a success. The project costs ranged from $\$ 12.50$ to $\$ 45.00$. The outsourcing fees were paid by the instructor through honorarium given by Intel Corporation with a total cost of under $\$ 100.00$. In every case, the programmers hired to do the outsourcing work completed the tasks as specified and on time. The outsourcing programmers proved to have high standards for their work, produced code that was well documented, and responded in a timely manner to 
questions and queries posted by the student project teams. The targeted program educational outcomes were all addressed.

Outcome a: an appropriate mastery of the knowledge, techniques, skills, and modern tools of their disciplines

Prior to working on the exercise, few of the students in the course were aware that an Internet based outsourcing service existed. Of the students that were aware of such services, all of them did not feel such a service or outsourcing endeavor could work. The activity of hiring a foreign programmer through the outsourcing service brought students to realize the Internet levels the playing field for programmers in the software industry. Most of the students saw the Internet in a new light as a tool to help solve programming problems by employing expertise from far places on the globe.

\section{Outcome e: an ability to function effectively on teams}

The extension of the project to a remote member brought home the aspect of globally distributed software development teams. The inclusion of the additional programmer late in the project development lifecycle forced the students to re-visit their team roles and take a look at the overall management of time and resources. The remote programmers forced at least one member of each team into a management role where this team member was responsible for the outcome of the outsourcing project.

\section{Outcome g: an ability to communicate effectively}

The difficulties of communicating outsourcing project requirements to a programmer that was both remote to the project and had English as a second language forced the project teams to be very specific on outsourced project requirements. In several cases, the hired programmer developed code and delivered a working program that was not what the project team had wanted, but was what the team had specified in their requirements. These cases forced the student teams to be very precise on requirements. In two of these cases, the project team ended up paying for additional work in order to get the outsourced project completed properly. Requiring students to be on the specification end of the project drove home the importance of communication. In all cases, the work received from the outsourcing programmer was well documented in English. This was an eye opener to students who typically would avoid documenting source code unless forced to do so by instructors.

Outcome j: a respect for diversity and a knowledge of contemporary professional, societal and global issues

In all cases, the students stated that they had no idea there were programmers outside the Unites States that could code to such high standards. The outsourcing programmers were from various geographic locations and were willing to do excellent work. Wages the students on the project teams paid the outsource programmers were initially viewed, by the students, to be very poor. However, after the suggestion was made to look up the average wage for a citizen in the 
countries outsource programmers resided; the students saw that these programmers were making reasonable wages indeed.

In all cases, the outsource programmer made a positive contribution to the student project, and all the students felt the price for the work was well worth the effort of project specification and management.

Below is an example of one of the projects. In this example, figure 1 shows the main web page for the distributed chess tournament site as the students had set it up prior to having the outsourcing programmer/web designer re-work the look and flow of the site. Figure 2 shows the main page of the site after the outsourcing programmer re-worked the graphics.

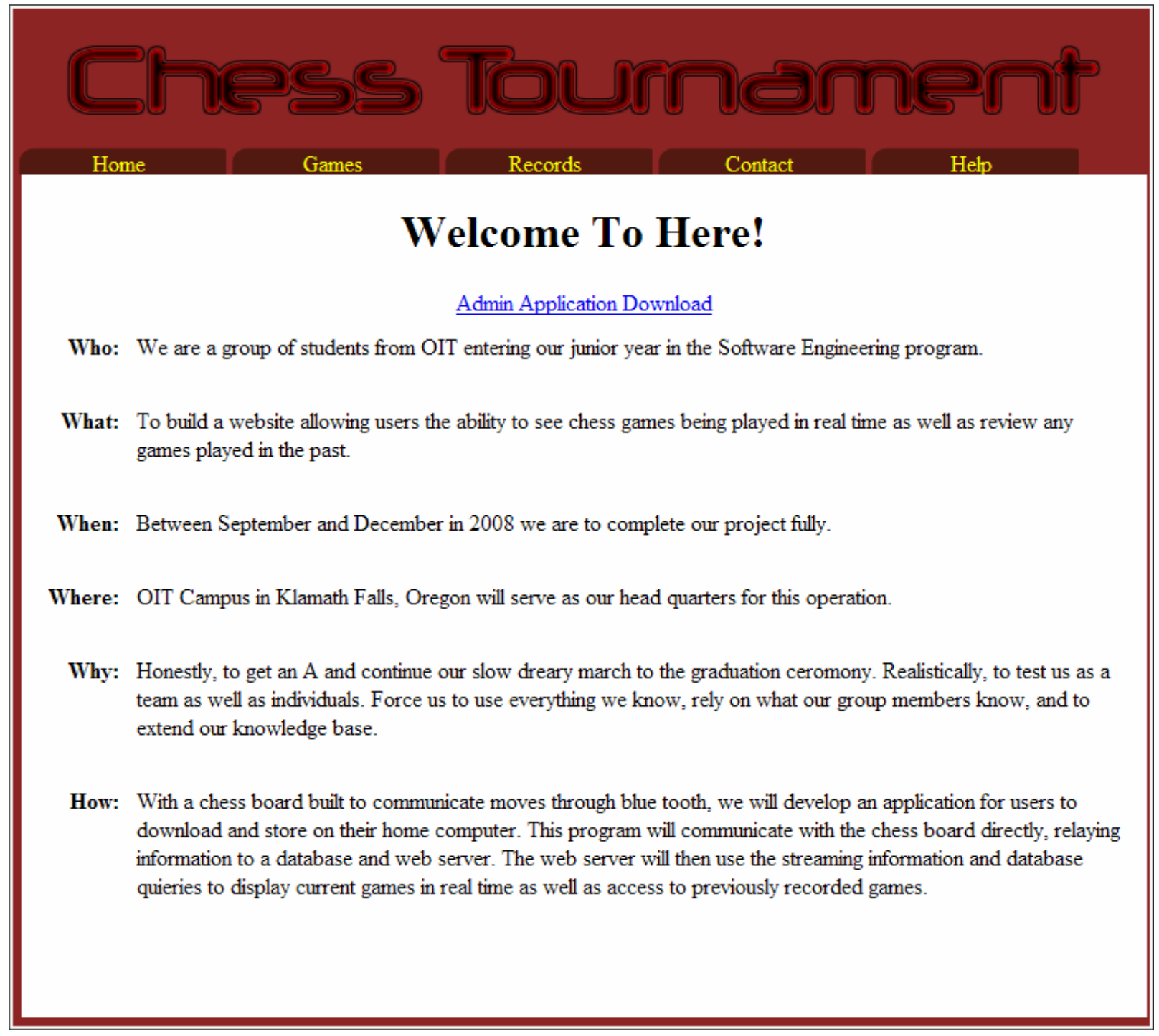

Figure 1 - The Chess Tournament main web page before it was worked on by the outsourcing programmer. 


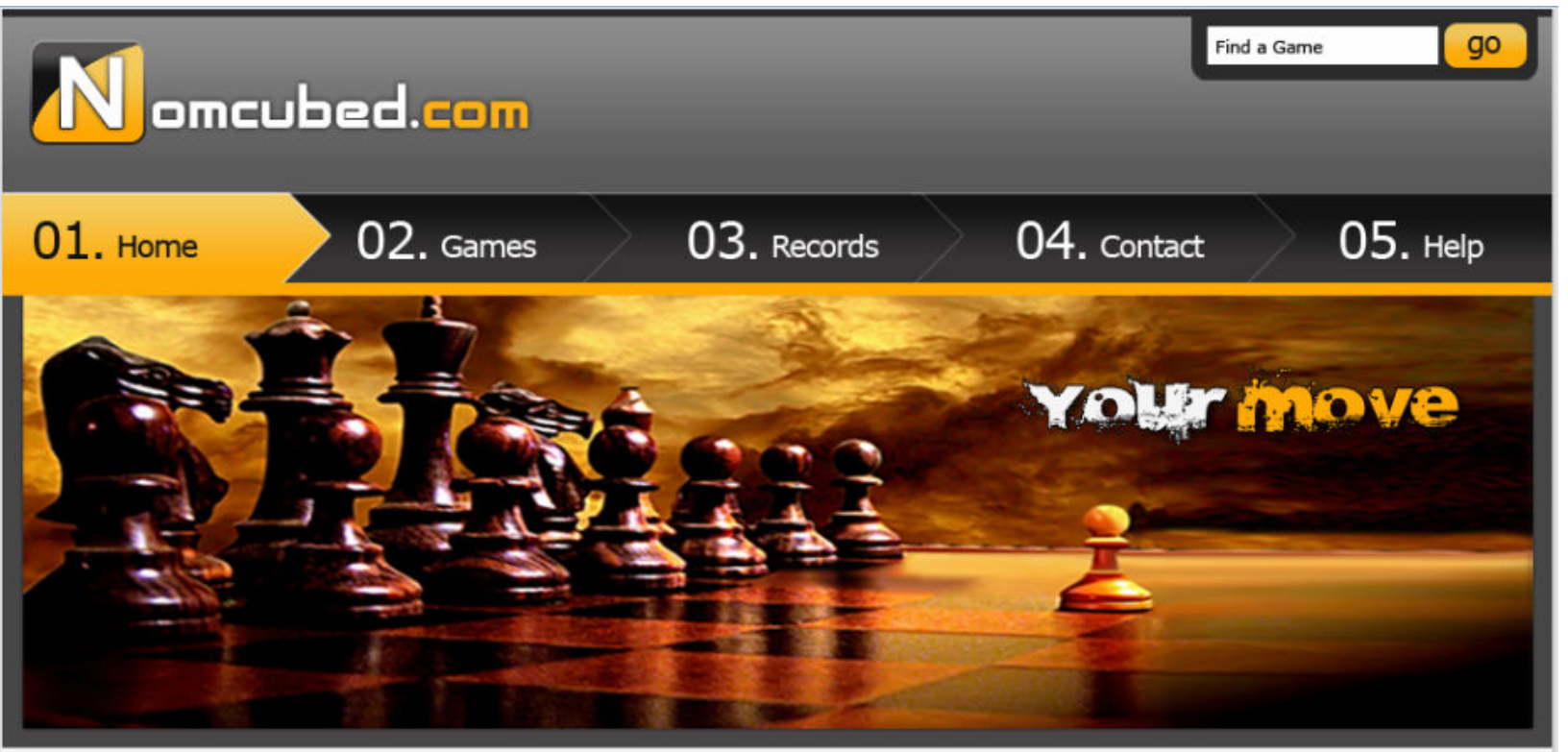

Welcome to Nomcubed.com

Who: We are a group of students from orr entering our junior year in the Software Engineering program.

What: To build a website allowing users the ability to see chess games being played in real time as well as review any games played in the past.

When: Between September and December in 2008 we are to complete our project fully.

Where: OIT Campus in Klamath Falls, Oregon will serve as our head quarters for this operation.

Why: Honestly, to get an A and continue our slow dreary march to the graduation ceromony. Realistically, to test us as a team as well as individuals. Force us to use everything we know, rely on what our group members know, and to extend our knowledge base.

How: With a chess board built to communicate moves through blue tooth, we will develop an application for users to download and store on their home computer. This program will communicate with the chess board directly, relaying information to a database and web server. The web server will then use the streaming information and database quieries to display current games in real time as well as access to previously recorded games.

Admin Application DOWNLOAD

Figure 2 - The Chess Tournament main web page after being re-worked by the outsourcing programmer.

\section{Lessons Learned}

The overall outcome of the project was a success. Students ended up with a new appreciation for systems analysis, design, and specification. This was especially enforced by working with a third party for system development. Students gained new knowledge of the software development world into which they were about to become employed. As a summary, students brought away the following ideas: 
1. Computer languages and software modeling languages are standardized making software development outsourcing a prime target for project cost cutting measures.

2. Software development engineers will request standardized modeling as a reference for work to be done. Until this exercise, students did not see real purpose in learning a graphical language for software structure.

3. The global software development work force has talented individuals willing to work for far less than a software developer in the United States.

4. Communication of ideas is key to effectively leveraging a global software development society as a software development resource.

5. With the Internet as a tool, teams can be effectively distributed across the globe.

6. Work pay scale is relative to where a person lives.

The assignment for the 2009-2010 school year will contain these modifications:

1. Students will be asked to write a short demographic study on the country and city in which the hired developer resides.

2. Students will be required to produce the hired developers' resume and indicate parts of the resume that were key for the hiring of the developer.

\section{Bibliography}

1. Engineering Technology and Engineering. Engineering Education and Practice in the United States: Engineering Technology Education. pp 13-15, National Academic Press, Washington DC, 1985

2. Rent-A-Coder outsourcing site activity. http://www.rentacoder.com

3. "IT Outsourcing Trends", Computer Economics, 2006

(http://www.computereconomics.com/article.cfm?id=1161)

4. "Outsourcing Trends to Watch in 2010", Computer World, December 2009

(http://www.computerworld.com/s/article/9142427/10_outsourcing_trends_to_watch_in_2010).

5. "Criteria for Accrediting Engineering Technology Programs, Effective for Evaluations During the 2010-2011

Accreditation Cycle". ABET Technology Accreditation Commission. October 2009.

(http://www.abet.org/Linked\%20Documents-UPDATE/Criteria\%20and\%20PP/T001\%2010-

11\%20TAC\%20Criteria\%2011-3-09.pdf ) 